\title{
MENINGKATKAN KEPUASAN KERJA KARYAWAN MELALUI PERENCANAAN KARIR INDIVIDU
}

\author{
Rahmi Widyanti \\ rahmiwidyanti@yahoo.com \\ Basuki \\ msibasukidr@gmail.com \\ Mursanto \\ Mursanto1965@gmail.com
}

Fakultas Ekonomi Universitas Islam Kalimantan MAB Banjarmasin

\begin{abstract}
The future is something that is uncertain for humans. Therefore, everyone tries to predict and plan for his/her future. Individual career planning is an important way to secure life. A career plan will help employees feel comfortable with their work and will directly affect job satisfaction. This study aims to analyze the relationship between individual career planning and employee job satisfaction for two types of university workers - academic and administrative staff. This research is also to understand whether the influence of individual career planning on job satisfaction is positive and significant. The research instrument using a questionnaire was distributed to 100 respondents at Uniska Banjarmasin. Statistical analysis with linear regression and tested using SPSS software for windows version 20.0.

The results of the study found that the existence of a clear career planning from the organization can increase job satisfaction positively and significantly.
\end{abstract}

Keywords: career planning, job satisfaction 


\section{PENDAHULUAN}

Kepuasan kerja karyawan dapatmenentukan sikap karyawan terhadap pekerjaannya, karyawan dengan tingkat kepuasan kerja yang tinggi memiliki perasaan positif tentang pekerjaantersebut, sedangkan seseorang yang tidakpuas memiliki perasaan yang negatif tentang pekerjaan tersebut. Organisasi yang memberikan kesempatan karyawan untuk maju dalam bekerja baik itu berupa pengetahuan maupun jabatan yang lebih tinggi, akan berdampak padakepuasan karyawan untuk kebutuhan aktualisasi diri dan dihargai dalam organisasi (Robbin dan Judge, 2015). Selain itu kepuasan kerja dapatmempengaruhi disiplin kerja karyawan kearah yang lebih baik, hal ini disebabkan karena karyawan telah mencapai kepuasan psikologis yang memunculkan sikap positifdari karyawan.(Rivai dan Sagala, 2015).

Luthans dalam Widyanti et al (2020) mengatakan dimensi dan indikator kepuasan kerja sebagai berikut 1)Faktor Ekstrinsik, merupakan faktor yang bersumber dari luar diri seorang pekerja yang memiliki indikator kepuasan terhadap gaji, keamanan kerja, kondisi kerja, status, kebijakan organisasi, mutu teknikpengawasan dan interaksi antar pegawai. 2)Faktor Intrinsik, merupakan faktor yang bersumber dari dalam diri seorang pegawai. Adapun indikatornya adalah Kepuasan terhadap pengakuan, tanggung jawab, prestasi, pekerjaan itu sendiri, kemungkinan untuk berkembang, dan kemajuan.

Perencanaan karir individu adalah satu area penelitian yang muncul untuk pembahasan akademis pada beberapa disiplin dari perspektif yang berbeda. Salah satu faktor dari perencanaan karir akan mempengaruhi kepuasan pekerjaan. Bagi karyawan, perencanaan karir dapat mendorong kesiapan diri mereka untuk menggunakan kesempatan karir yang ada, sedangkan bagi organisasi akan mempermudah pemenuhan kebutuhan penyusunan personalia (staffing) internal organsasi, sehingga akan meningkatkan kinerja dan produktivitas karyawan, 
menurunkan turn over dan akan memberi kesempatan promosi bagi karyawannya (Dessler, 2017). Bagaimanapun juga, hal ini penting untuk melakukan pembahasan secara empiris dengan lingkungan kerja berbeda untuk menyediakan bukti untuk pengaruh dengan pekerjaan berbeda pada hubungan antara perencanaan karier dan kepuasan pekerjaan. Penelitian ini bertujuan untuk menguji hubungan antara perencanaan karir individu dan kepuasan kerja karyawan untuk dua jenis pekerjaan yaitu akademisi dan staf administratif. Hal ini untuk memahami apakah perencanaan karir individu dan pengaruhnya terhadap kepuasan kerja karyawan pada Universitas Islam Kalimantan.

\section{TINJAUAWAN PUSTAKA}

Kepuasan kerja merupakan hal penting yang dimiliki individu di dalam bekerja. Tinggi rendahnya kerja sangat tergantung pada sikap mental individu yang bersangkutan karena kepuasan kerja adalahcermin dari perasaan seseorang terhadap pekerjaannya. Luthans dalam Rivai et al (2015) mengatakan dimensi dan indikator kepuasan kerja sebagai berikut 1)Faktor Ekstrinsik, merupakan faktor yang bersumber dari luar diri seorang pekerja yang memiliki indikator kepuasan terhadap gaji, keamanan kerja, kondisi kerja, status, kebijakan organisasi, mutu teknikpengawasan dan interaksi antar pegawai. 2)Faktor Intrinsik, merupakan faktor yang bersumber dari dalam diri seorang pegawai. Adapun indikatornya adalah Kepuasan terhadap pengakuan, tanggung jawab, prestasi, pekerjaan itu sendiri, kemungkinan untuk berkembang, dan kemajuan.

Baruch (2004) menyatakan perencanaan Karir dan manajemen (CPM) punya berpengaruh signifikan, terutama pada area manajemen sumber daya manusia (HRM). Farmer et al dalam Widyanti R., 2012 . menyatakankan bahwa perlu mendiskripsikan satu pekerjaan dan satu karir sebelum mendefinisikan masa 'perencanaan karir'. Selanjutnya karir dapat diartikan sebagai jaminan lapangan kerja 
dengan suatu organisasi selama seumur hidup, dimana individu mengalami peningkatan karir pada sejumlah posisi yang berbeda (Dessler, 2017).

Hall et al (dalam Widyanti R., 2021). mendefinisikan karier sebagai " ide dalam memilih satu jabatan seperti rata-rata dari suatu kemajuan yang dilalui selama hidup." Demikian juga, secara menyeluruh definisi dari karir diberikan oleh Baruch dan Rosenstein sebagai "satu proses dari pembangunan diri karyawan sepanjang satu alur pengalaman dan pekerjaan pada organisasi." Aryee dan Debrah menyoroti perencanaan karir sebagai suatu taraf aktivitas pekerjaan individu, pengembangan karir adalah suatu tahapan aktivitas pekerjaan dalam organisasi. Sesuai dengan Gutteridge, pengembangan karir menunjuk kepada spesifikasi aktivitas sumber daya manusia untuk mencocokan kesempatan individu dan pekerjaan. Perencanaan Karir adalah sebagai "satu kursus proaktif di pembentukan satu efektif karir yang mungkin dipengaruhi oleh lokus dari kontrol. " Seperti dikutip oleh Aryee dan Debrah, (Widyanti R., 2020) menjelaskan perencanaan karir sebagai " satu proses sengaja dari menjadi sadar akan diri, kesempatan, batasan, pilihan dan konsekwensi; mengidentifikasi karier berhubungan gol; dan pekerjaan program, Pendidikan dan pengalaman pengembangan yang terkait untuk menyediakan arah, pemilihan waktu dan urutan dari tahapan untuk mencapai satu gol karier spesifik". Baruch (20040 menyatakan bahwa perencanaan karir dan manajemen yang berpengaruh signifikan, terutama pada area manajemen sumber daya manusia (HRM). CPM adalah satu area HRM yang memerlukan upaya khusus dari dua organisasi dan perorangan. Konsep dengan perencanaan karir organisasi didefinisikan oleh Baruch sebagai “ satu pendekatan menyeluruh terhadap semuanya aktivitas dan ilmu pengetahuan tentang teknik dimudahkan oleh organisasi yang mana mempunyai kaitan dengan pengembangan karir dari karyawan." PenelitianKayalar dan Ozmutaf (2009) menemukan perencanaan karir individu meningkatkan kepuasan kerja, sehingga perencanaan karier individu berpengaruh kepadakepuasan kerja. Oleh karenanya organisasi harus 
memperhatikan dan mengelola perencanaan dan pengembangan karier setiap karyawan dengan baik. Hal inibertujuan agar karyawan mempunyai kemampuan yang lebih tinggi, sehingga lebih dapat mengetahui fungsi dan peranan serta tanggung jawabnya di dalam lingkungan kerja. Melalui perencanaan dan pengembangan karir diharapkan dapat mencapai tingkat kepuasan kerja yang lebih tinggi dan mendapat kejelasan akan jenjang karir yang akan mereka capai. Organisasi berusaha untuk menumbuhkan kepuasan kerja yang sehat, dimana hak dan kewajibankaryawan selaras dengan fungsi peranan dan tanggung jawab karyawannya. Pembahasan dari Hall dkk (Widyanti R., 2021). disebutkan perencanaan karir sebagian besar terlaksana oleh organisasi. Seperti dikutip oleh McCabe bahwa konsep dari ' karir baru ' dan ' alur karir baru punya dimuncul berlandaskan dugaan dari Mallon bahwa pekerjaannya perorangan jaminan sekuritas dijangkar tidak ke satu organisasi kecuali padanya / kas suratnya sendiri dari keterampilan portabel dan employability pribadi. Faktor yang paling berpengaruh nyata mempengaruhi perencanaan karir individu meliputi umur, gender, Pendidikan, sosial, dinamika ekonomi dan lingkungan. Barnett et al., 2007 menyatakan bahwa satu kebutuhan individu proaktif, lentur, dan pelihara satu jangkauan keterampilan inti dan kemampuan seiring dengan pengalaman profesional. Pembahasan yang sudah ada menekankan pengaruh dari harga diri menyangkut keputusan dan perilaku karir, dan oleh karenanya, diharapkan oleh individu dengan menngkatnya rasa harga diri lebih mungkin perencanaan karir mereka dibandingkan itu dengan harga diri yang rendah. Kepuasan kerja yang telah secara luas dipaparkan, merupakan sebagai salah satu determinan penting dari perencanaan karir individu. Robbin, 2016, mendefinisikan kepuasan kerja sebagai “ satu fungsi dari perasa hubungan di antara apa yang seseorang mau dari pekerjaannya dan apa seseorang merasa ini sebagai sesuatu yang sudah diberikannya ". Kepuasan kerja menunjukkan sikap individu ke berbagai arah aspek dari pekerjaan mereka seperti halnya pekerjaan pada umumnya. 
Konsep dari kepuasan kerja telah diuji di berbagai aspek dan dipertimbangkan oleh ahli sosiologi dan ahli psikologi industri. Kepuasan kerja sebagai mediator hubungan antara karyawan dengan lingkungan kerjanya, baik secara hasil organisatoris maupun individu.

Berdasarkan penjelasan di atas, maka dapat digambarkan kerangka konseptual sebagai berikut:

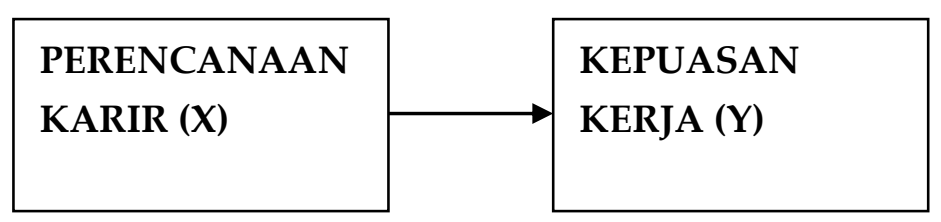

\section{METODE PENELITIAN}

Metode yang digunakan dalam penelitian ini adalah metode kuantitatif yaitu untuk menguji pengaruh dari perencanaan karir individu pada kepuasan kerja. Khususnya, perbedaan dan persamaan di antara akademis dan staf administratif Universitas. Instrumen penelitian ini menggunakan angket dan telah dibagikan kepada 100 orang baik tenaga maupun tenaga administrasi dari universita Islam Kalimantan secara purposive random sampling (Basuki, 2021). Sebanyak 100 staf universitas berpartisipasi sebagai responden.

Uji validitas dan reliabilitas dilakukan sebelum angket dibagikan. Konsisten internal dari angket telah divalidasi melalui analisis korelasi Product Moment dan Alfa Cronbach. Dengan menggunakan software SPSS for windows versi 20.0. Skala Likert dipergunakan antara skala 1 sampai dengan skala 4

\section{HASIL PENELITIAN DAN PEMBAHASAN}

Pada Tabel 1 menunjukan distribusi dari jenis kelamin responden, distribusi jenis dari pekerjaan ditunjukkan pada Tabel 3. Kebanyakan dari responden adalah laki-laki di keduanya akademisi dan staf administratif. 


\section{Tabel 1}

Jenis Kelamin Responden

\begin{tabular}{|c|c|c|}
\hline Jenis Kelamin & Frekuensi & Persen \\
\hline Perempuan & 45 & 45 \\
\hline Laki-laki & 55 & 55 \\
\hline Jumlah & 100 & 100 \\
\hline
\end{tabular}

Sumber: Data primer, diolah, 2020

Tabel 2

Usia Responden

\begin{tabular}{|c|c|c|}
\hline Usia & Frekuensi & Persen \\
\hline $25-29$ & 12 & 36 \\
\hline $30-34$ & 36 & 40 \\
\hline $35-39$ & 40 & 10 \\
\hline $40-44$ & 10 & 100 \\
\hline $45+$ & 100 & 8 \\
\hline Jumlah & & \\
\hline
\end{tabular}

Sumber: Data primer, diolah, 2020

Tabel 2 menggambarkan distribusi dari umur responden oleh jenis dari pekerjaan.

Sementara umur tempat latihan dari personalia akademis $(\mathrm{n}=100)$ adalah $25-55$, arti dan kesalahan st. adalah $34.8 \pm 7.05$, berturut-turut. Dengan cara yang sama, umur tempat latihan dari tenaga administrasi $(n=54)$ adalah 25 - 49, arti dan kesalahan st. adalah $35.4 \pm 7.43$, berturut-turut.

\section{Tabel 3}

Jumlah Responden berdasarkan Jenis Pekerjaan

\begin{tabular}{|c|c|c|c|}
\hline No. & Jenis Pekerjaan & Jumlah & Persen \\
\hline
\end{tabular}




\begin{tabular}{|c|c|c|c|}
\hline 1. & Akademisi & 58 & 58 \\
\hline 2. & Staf Admistrasi & 42 & 42 \\
\hline & Jumlah & 100 & 100 \\
\hline
\end{tabular}

Sumber: Data primer, diolah, 2020

Berdasarkan Tabel 3 menunjukkan bahwa sebagian besar responden yang berpartisipasi dalam penelitian ini adalah akademisi sebanyak $58 \%$. Hal ini meunjukkan bahwa akademi telah merencanakan karirnya sejak awal karena sudah jelas aturan kepegawaian tentang karir dosen. Bagi staf administrasi pada perguruan tinggi swasta belum berjalan sebagaimana di instansi pemerintah.

Tabel 4

\section{Rangkuman Hasil Analisis Regresi Linier Berganda}

\begin{tabular}{|c|c|c|c|c|c|c|}
\hline $\begin{array}{l}\text { Variabel } \\
\text { Terikat }\end{array}$ & Variabel Bebas & $\begin{array}{c}\text { Koefisie } \\
\mathbf{n} \\
\text { Regresi }\end{array}$ & $t_{\text {hitung }}$ & Sig & $\mathbf{r}_{\text {partial }}$ & $\mathbf{r}_{\text {partial }}{ }^{2}$ \\
\hline $\begin{array}{c}\text { Kepuasan } \\
\text { Kerja } \\
\text { (Y) }\end{array}$ & $\begin{array}{l}\text { Perencanaan Karir } \\
\qquad(\mathrm{X})\end{array}$ & 0,257 & 2,522 & 0,013 & 0,246 & 0,060 \\
\hline $\begin{array}{l}\text { Konstanta } \\
\mathrm{R} \\
\mathrm{R} \text { Square } \\
\text { Adjusted R Square }\end{array}$ & $\begin{aligned}= & 9.092 \\
& =0,548 \\
& =0,300 \\
& =0,286\end{aligned}$ & & $\begin{array}{l}\mathrm{F} \text { hitung } \\
\text { Sig } \mathrm{F} \\
\mathrm{F} \text { tabel } \\
\mathrm{t} \text { tabel } \\
\text { SEE }\end{array}$ & $\begin{array}{l}=21 \\
=0, \\
=3, \\
=1, \\
=0\end{array}$ & & \\
\hline
\end{tabular}

Sumber : Data Olahan, 2020 (lampiran)

Berdasarkan Tabel 4 di atas diketahui bahwa nilai thitungdari variabel

Perencanaan Karir $(X)$ sebesar 2,522 dan Nilai tabel sebesar 1,660. Dengan 
membandingkan nilai thitung dengan ttabel dengan taraf nyata 5\%, dimana thitung $(2,522)>$ ttabel $(1,660)$, dan nilai signifikansi sebesar 0,01 atau tidak melebihi dari 0,05, maka Ha diterima dan Ho ditolak. Sehingga dapat disimpulkan bahwa secara parsial Kualitas Pelayanan berpengaruh signifikan terhadap Kepuasan kerja karyawan. Sedangkan besarnya pengaruh Perencanaan Karir terhadap Kepuasan Kerja dalam penelitian ini diketahui dari nilai r parsial yang dikuadratkan atau r2 yaitu sebesar 0,160 yang berarti bahwa dimensi ini memberikan kontribusi terhadap terhadap Kepuasan kerja pegawai di Universitas Islam Kalimantan MAB sebesar $16 \%$ baik pegawai akademisi maupun staf administrasi.

\section{PEMBAHASAN}

Horizon perencanaan karir individu lebih baik pada akademis dibandingkan responden dari staf administrative, apakah seseorang setelah tiga tahun. Bahwasanya, empat atau tahun lebih tinggi dari horizon perencanaan diharapkan dari personalia akademis.

Berdasarkan Tabel 4 di atas diketahui bahwa nilai thitungdari variabel

Perencanaan Karir $(X)$ sebesar 2,522 dan Nilai tabel sebesar 1,660. Dengan membandingkan nilai thitung dengan ttabel dengan taraf nyata 5\%, dimana thitung $(2,522)>$ ttabel $(1,660)$, dan nilai signifikansi sebesar 0,01 atau tidak melebihi dari 0,05, maka Haditerima dan Ho ditolak. Sehingga dapat disimpulkan bahwa secara parsial Perencanaan Karir berpengaruh signifikan terhadap Kepuasan kerja karyawan Universitas Islam Kalimantan MAB. Sedangkan besarnya pengaruh perencanaan karir 
terhadap Kepuasan Kerja dalam penelitian ini diketahui dari nilai rparsial yang dikuadratkan atau r2 yaitu sebesar 0,160 yang berarti bahwa dimensi ini memberikan kontribusi terhadap terhadap Kepuasan kerja karyawan Universitas Islam Kalimantan MAB sebesar $16 \%$. Satu keterangan mungkin dari ini adalah dampak dari asisten penelitian dari sekolah lulus meneliti asisten itu tidak mempunyai jaminan lapangan kerja setelah pelengkap utama mereka dan / atau derajat doktoral. Menyoroti staf administratif juga akan untuk naik pangkat pada departemen lain di satu ke tiga tahun. Demikian juga, pertanyaan dari apakah aktivitas perencanaan karier perorangan meningkatkan kepuasan kerja kebanyakan telah diterima secara positif menanggapi (sering, selalu) oleh partisipan akademis seperti mereka kebanyakan menentukan alur karier mereka sendiri perorangan. Tenaga administrasi, bagaimanapun, kebanyakan memilih " kadang kala atau " selalu yang dipilih, seperti karier mereka ditentukan oleh faktor lain seperti hubungan, Politik, ketidak-setujuan dengan manajer dan seterusnya. Tenaga administrasi dalam penelitian ini mereka sendiri lebih produktif. Sejak tugas dari tenaga administrasi adalah operasional standar tergambar dengan baik seperti prosedur, produktifitas mereka dapat dikaji lebih mudah oleh ketentuan obyektif. Meskipun demikian, penilaian produktifitas dari personalia akademis jadilah lebih sulit sehubungan dengan variabilitas dan kesubyektipan dari faktor evaluasi.

Kepuasan kerja dan kebahagiaan adalah lebih tinggi untuk personalia akademis, kemungkinan karena akibat kepribadia sosial lebih tinggi. Karenanya, tidak anehnya lagi saran yang akademis pekerjaan mereka ke lain-lain. Cukup perbedaan berpengaruh nyata di antara akademis dan tenaga administrasi telah ditemukan pada organisatoris dan gol perorangan Dengan jelas, kinerja dari personalia akademis adalah elemen kritis untuk mencapai bidang pendidikan dan tujuan ilmiah dari universitas. 
Tenaga administrasi punya peran yang mendukung untuk mencapai tujuan itu. Dengan kata lain, sementara personalia akademis meningkatkan karir mereka oleh mereka penelitian akademis dan pengalaman pengajaran, mereka juga menolong mereka universitas untuk menjangkau tujuan organisatoris mereka. Dengan demikian, tujuan dari akademis sesuai personalia dari universitas.

\section{KESIMPULAN}

Hasil keseluruhan dari penelitian pengaruh perencanaan karier dalam meningkatkan kepuasan kerja. Secara signifikan perencanaan karir individu berpengaruh positif terhadap kepuasan kerja karyawan di Universitas. Personalia akademis mengerjakan lebih produktif dan mempunyai kepuasan kerja yang lebih tinggi dikarenakan sudah jelas jenjang karirnya dari tenaga pengajar sampai dengan guru besar. Oleh sebab itu, dapat disimpulkan perencanaan karir individu akan dapat meningkat kepuasan kerja dari personalia akademis dan non akademis.

\section{DAFTAR PUSTAKA}

Barnett, Renee, Belinda and Bradley, Lisa, 2007, The impact of organizational support for career development on career satisfaction, Journal of Career Development International, Vol. 12, No.7, pp.617-636.

Baruch, Y. 2004, Transforming Career from Linear to multidirectional career paths, Organizational and individual perspective, Career Development International, Vol.9, No.1, pp. 58-73. Emerald Group.

Basuki, 2021, Pengantar Metode Penelitian Kuantitatif, Penerbit Media Sains Indonesia,Bandung, https://scholar.google.co.id/citations?user=ka0E86IAAAAI

Basuki, 2015, Pengaruh Praktik Sumber Daya Manusia Strategik Dan Knowledge Management Terhadap Kinerja Organisasi, Jurnal Al Kalam, Komunikasi Bisnis dan Manajemen, Vol.2 No.4 Juli 2015.

Dessler, Gary 2007, Manajemen Sumber Daya Manusia, Edisi Bahasa Indonesia, alih bahasa Drs Benyamin Molan, Edisi Ke-10 Prentice Hall Inc.

137

Jurnal Komunikasi Bisnis dan Manajemen

Vol. 8 No. 2 Juli 2021 
Harunnurrasyid., Rahmi Widyanti, 2018, Faktor-Faktor Yang Mempengaruhi Orientasi Karir Individu (Suatu Tinjauan Teoritis), Jurnal Al Kalam Komunikasi Bisnis dan Manajemen, Vol.5 No.1 Januari 2018.

Hofmans, Dries, Pepermans, 2008, The Career Satisfaction Scale : Response bias among men and woman, Journal of Vacatioal Behavior, Vol. 73, pp.397-403 Elsevier.com.

Kalayar, Murat and Ozmutaf, Metin, 2009, The Effect of Individual Career Planning on Job Satisfaction : A Comparative Study On Academic And Administrative Staff, The Journal of Faculty of Economics and Administrative Sciences, Vol. 14, pp.239-254.

Widyanti, R., Thoyib, A., 2012, The Perception Of Individual And Organizational Careers In Increasing The Organizational Commitment, Journal of Economics, Business, \& Accountancy Ventura 15 (2), 231-244.

Widyanti, Rahmi, 2021, Manajemen Karir, Penerbit Media Sains Indonesia, Bandung, https://scholar.google.co.id/citations?user=ka0E86IAAAAI

Widyanti R., Basuki. Kurniaty. Zainul M., Alfisah Erni., Susiladewi, Purboyo, 2020, The linked of role career-based anchors and organizational commitment in disruption era: Evidence from plywood corporate staff in south Kalimantan, International Journal of Advanced Science and Technology, 2020, 29(5), pp. 2731-2738. 